\title{
Resistance Performance of a Vortex Tube Separator by Numerical Calculations
}

\author{
Dawei Wang ${ }^{1, *}$ and Xiaojuan Luan ${ }^{2}$ \\ ${ }^{1}$ School of Energy Science and Engineering, Harbin Institute of Technology, Harbin 150001, Heilongjiang, China \\ ${ }^{2}$ Wuhan Boiler Group Co., Ltd, Wuhan 430070, Hubei, China \\ *Corresponding author
}

\begin{abstract}
The vortex tube which is used to separate the dust of air flowing in the engine can reduce or eliminate the damage of the dust to the engine and guarantee its security. Total pressure loss performace is presented through Navier-Stokes equation and standard turbulence model. This paper shows the influence of SCR (scavenge ratio) and main flow to the total pressure loss ; Results show that the total pressure loss curves obtained by numerical simulation agree well with that of the experiment, indicting high precision of numerical simulation method in this aspect.
\end{abstract}

Keywords- vortex tube; SCR; numerical simulation; experiment study

\section{INTRODUCTION}

When a helicopter flies at a super low height and hovers,a lot of dust, ice, snow and other exotic things will be sucked into the engine under the influence of its rotors. In this way, these exotic things will do damage to the engine which will lower its performance and power, shorter its life[1]. Installing high separation efficiency preventer at the inlet of the engine as a effective way to protect the helicopter can reduce or eliminate the damage of the dust to the engine, extend the helicopter's service life, guarantee its security, improve battle ability and equipment guarantee ability[2].

Multi-tubes inertia equipment is widely used in the helicopter to stop the dust now. Multi-tubes inertia equipment is made up of many vortex tubes for different purposes. That is to say, the vortex tube is the core element. This paper uses a single vortex tube as study object to examine character factor's effect to its performance,and provides reference for the research and development of new products[3,4].

\section{NUMERICAL SiMUlation}

\section{A. Calculation Domain}

Unlike conventional annular scavenging ports, the model used here has its three scavenging ports located on the wall side. In order to set the fluid's direction of scavenging ports accurately, this paper adds annular space at the outside of the scavenging ports and defines it as the scavenging port for numerical simulation. Front tube and rear tube having the same diameter with the vortex tube are installed to reduce the impact of vortex tube upstream and downstream to its airflow field.

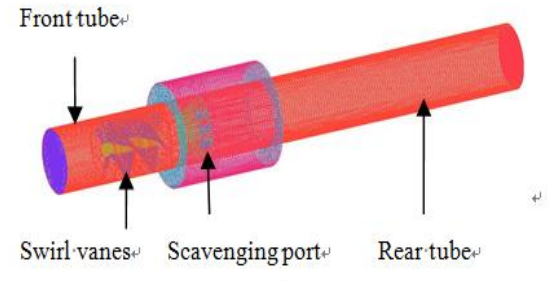

FIGURE I. CALCULATION MODEL

\section{B. Governing Equations}

Any flow problems must comply with the law of conservation of mass, the law of conservation of momentum , the law of conservation of energy, and their expressions are as follows ${ }^{[5]}$ :

Mass equation:

$$
\frac{\partial \rho}{\partial t}+\frac{\partial}{\partial x_{i}}\left(\rho u_{i}\right)=0
$$

Momentum equation:

$$
\frac{\partial}{\partial t}\left(\rho u_{i}\right)+\frac{\partial}{\partial x_{j}}\left(\rho u_{i} u_{j}\right)=-\frac{\partial p}{\partial x_{i}}+\frac{\partial \tau_{i j}}{\partial u_{j}}
$$

Energy equation:

$$
\frac{\partial}{\partial t}\left[\rho\left(e+\frac{u_{i} u_{i}}{2}\right)\right]+\frac{\partial}{\partial x_{j}}\left\{u_{j}\left[\rho\left(e+\frac{u_{i} u_{i}}{2}\right)+p\right]\right\}=\frac{\partial}{\partial x_{i}}\left(\kappa \frac{\partial T}{\partial x_{i}}+u_{j} \tau_{i j}\right)
$$

where $\rho$ is fluid density, $\mathrm{t}$ is time, $\tau_{i j}$ is viscous stress tensor, e is internal energy per unit mass, $\kappa$ is coefficient of heat transfer, $\delta_{i j}$ is unit tensor.

Based on the Boussinesq assumption, the above incompressible viscosity gas $\mathrm{N}-\mathrm{S}$ equations ignoring the mass force are obtained. 
The vortex viscosity coefficient is simulated by $k-\varepsilon$ turbulence model. Standard $k-\varepsilon$ model gets the solution of $k$ and $\varepsilon$ through solving $k$ equation and $\varepsilon$ equation. Standard $k-\varepsilon$ `s transport model equations as follows:

$$
\frac{\partial(\rho k)}{\partial t}+\frac{\partial\left(\rho \kappa u_{i}\right)}{\partial x_{i}}=\frac{\partial}{\partial x_{j}}\left[\left(\mu+\frac{\mu_{t}}{\sigma_{k}}\right) \frac{\partial k}{\partial x_{j}}\right]+G_{k}+G_{b}-\rho \varepsilon-Y_{M}+S_{K}
$$

$$
\frac{\partial(\rho \varepsilon)}{\partial t}+\frac{\partial\left(\rho \varepsilon u_{i}\right)}{\partial x_{i}}=\frac{\partial}{\partial x_{j}}\left[\left(\mu+\frac{\mu_{t}}{\sigma_{\varepsilon}}\right) \frac{\partial \varepsilon}{\partial x_{j}}\right]+\frac{C_{1 \varepsilon} \varepsilon}{k}\left(G_{k}+C_{3 \varepsilon} G_{b}\right)-C_{2 \varepsilon} \rho \frac{\varepsilon^{2}}{k}+S_{\varepsilon}
$$

The remaining coefficients as follows:

$$
C_{1 \varepsilon}=1.44, C_{2 \varepsilon}=1.92, C_{\mu}=0.09, \sigma_{k}=1.0,
$$
$\sigma_{\varepsilon}=1.3$.

\section{Boundary Conditions}

A single vortex tube is used to proceeding gas-solid twophase numerical simulation. 300K;

Inlet: pressure inlet, pressure is $101325 \mathrm{~Pa}$, temperature is

Main outlet: mass outlet, setting the flow rate we need;

Scavenging outlet: pressure outlet, setting the pressure according to the SCR;

Wall: adiabatic and no slip, default surface roughness is 0.5 .

\section{NumERICAL SimUlation Results AND ANALYSIS}

In order to observe the flow characteristics in a vortex tube in detail, Fig. 2 shows a vortex tube's contour of velocity distribution in vertical section when main flow is $85.75 \mathrm{~g} / \mathrm{s}$, SCR is $8 \%$. Fig. 3 shows contour of velocity distribution in different cross sections. Fig. 4 shows velocity vectors on vanes section.

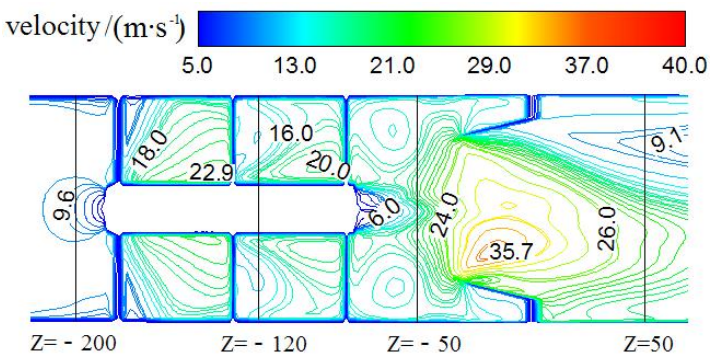

FIGURE II. CONTOUR OF VELOCITY DISTRIBUTION IN VERTICAL SECTION
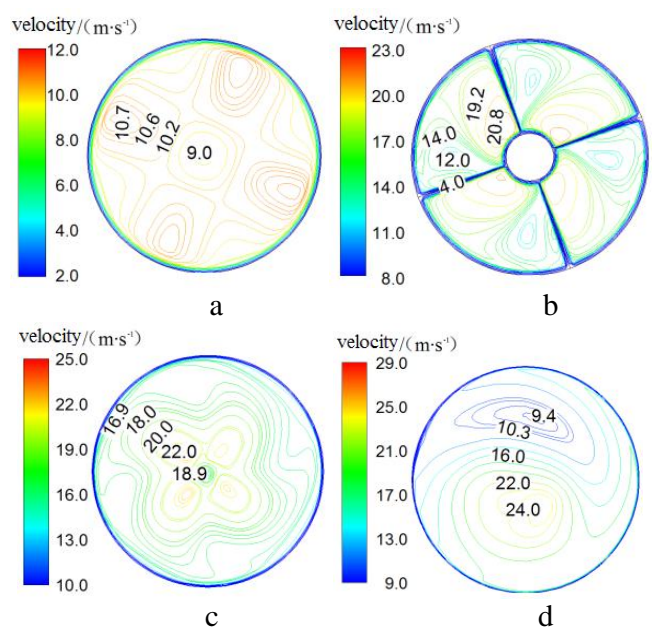

FIGURE III. CONTOUR OF VELOCITY DISTRIBUTION IN DIFFERENT CROSS SECTIONS

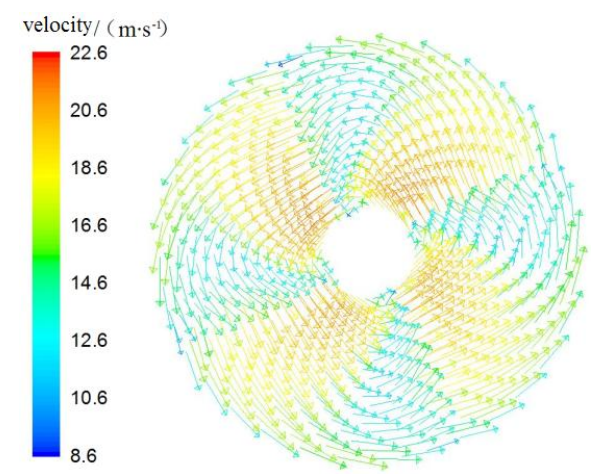

FIGURE IV. VELOCITY VECTORS ON VANES SECTION

Fig. 2 - 4 shows the changes of airflow velocity from the front tube to the rear tube. At the entrance of the vortex tube ,the airflow has started rotating because of the presence of swirl vanes and the airflow rate gradually increases along the radial direction; In the swirl vanes area, the airflow velocity begins to increase and velocity is on the decrease along the circumferential in every basin; After the swirl vanes, airflow under high rotation speed forms a low-velocity zone behind the shaft and airflow velocity increases firstly and then decreases along the radial direction; The airflow velocity is further improved after flowing through the diffuser pipe. Because of the scavenging effects, airflow velocity is not symmetrical distribution. The maximum velocity appears on one side of the rear tube, and it gradually decreases towards both sides. This shows that the swirl vanes and the diffuser pipe have great influences on the airflow.

Fig. 5 shows a vortex tube's contour of total pressure distribution in vertical section when main flow is $85.75 \mathrm{~g} / \mathrm{s}$, SCR is $8 \%$.Figure 6 shows contour of total pressure distribution in different cross sections. From Fig. 5 and Fig. 6, we can see that total pressure isobars are closely concentrated in the swirl vanes, the rare cylinder of the shaft and the diffuser pipe. Most of the pressure loss is caused by the turbulence caused by swirl vanes and structural changes. 


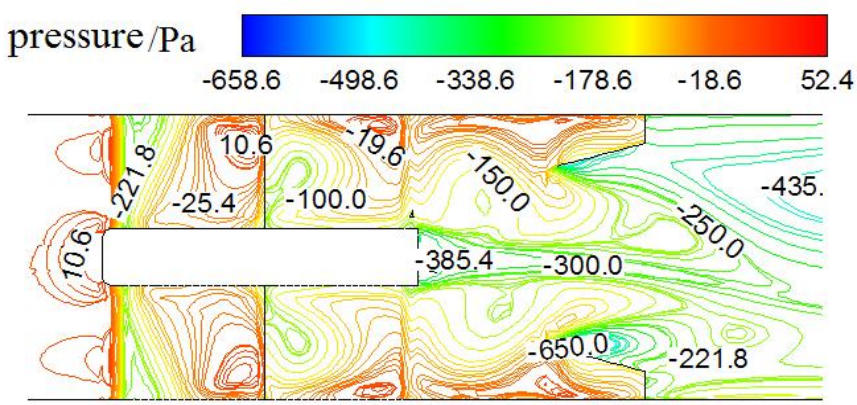

FIGURE V. CONTOUR OF TOTAL PRESSURE LOSS DISTRIBUTION IN VERTICAL SECTION

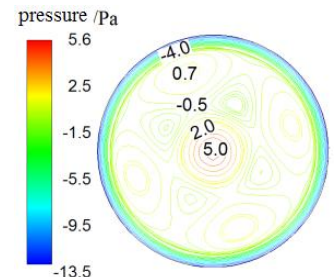

(a) $\mathrm{Z}=-200$

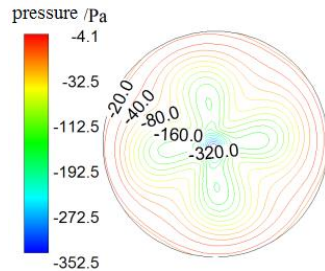

(c) $\mathrm{Z}=-50$

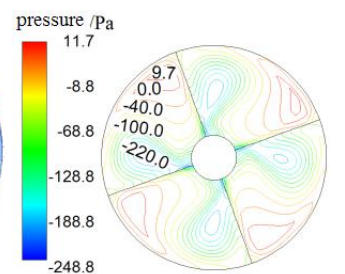

(b) $Z=-120$

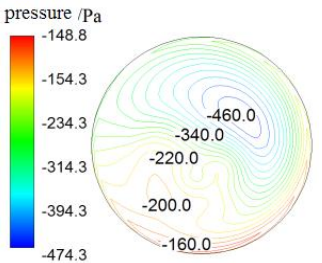

(d) $\mathrm{Z}=50$
FIGURE VI. CONTOUR OF TOTAL PRESSURE LOSS IN DIFFERENT CROSS SECTIONS

SCR and main flow have effects on the vortex tube's pressure loss. Fig. 7 shows the influence of SCR to the pressure loss at the main flow of $61.25 \mathrm{~g} / \mathrm{s}$. Fig. 8 shows the influence of main flow to the pressure loss at SCR of $8 \%$. From the figures we can see the vortex tube`s pressure loss increases as SCR and main flow increase. Compared to the SCR, the main flow has a greater impact on total pressure loss in the vortex tube.

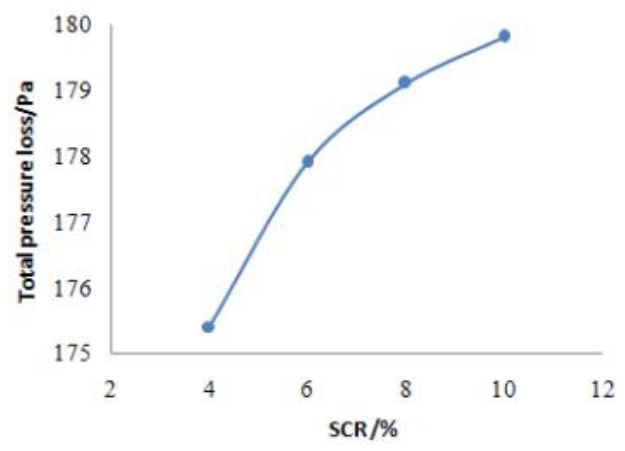

FIGURE VII. THE INFLUENCE OF SCR TO THE PRESSURE LOSS

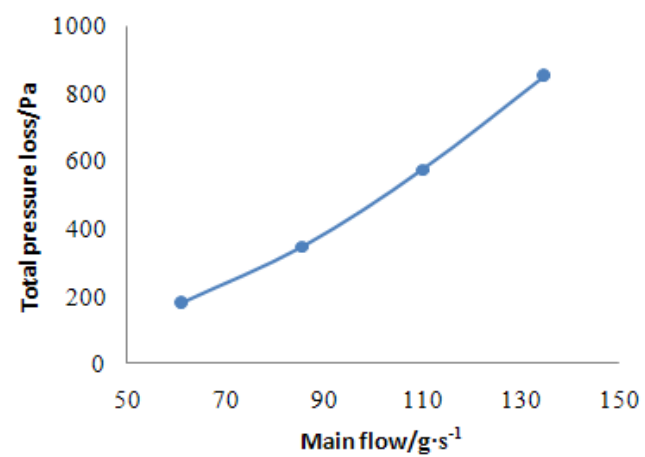

FIGURE VIII. THE INFLUENCE OF MAIN FLOW TO THE PRESSURE LOSS

\section{EXPERIMENTAL RESULTS OF RESISTANCE CHARACTERISTICS LYSIS}

Resistance characteristic on behalf of the vortex tube energy consumption is an important index of its performance. The vortex tube generally works in normal temperature and pressure conditions. Adopting the environmental pressure and temperature conditions, experimental study on resistance characteristic is carried on in the inhaled wind tunnel experimental bench. This condition ensures that the working state of vortex tube separator is almost equal to the real one. After making the experimental model according to the simulation model, we strictly build the vortex tube test system based on experimental model and conduct resistance experiments.

Fig. 9 shows resistance characteristic curve at different SCR and main flow. It figures out that compared to the SCR, the main flow has a greater impact on resistance loss in the vortex tube, which is the same as numerical simulation result. Fig.9 shows numerical simulation results and experiment results. As a result of the two resistance characteristic curves are in good agreement, this can illustrate the numerical simulation method in the acquisition of a vortex tube resistance characteristics has high accuracy.

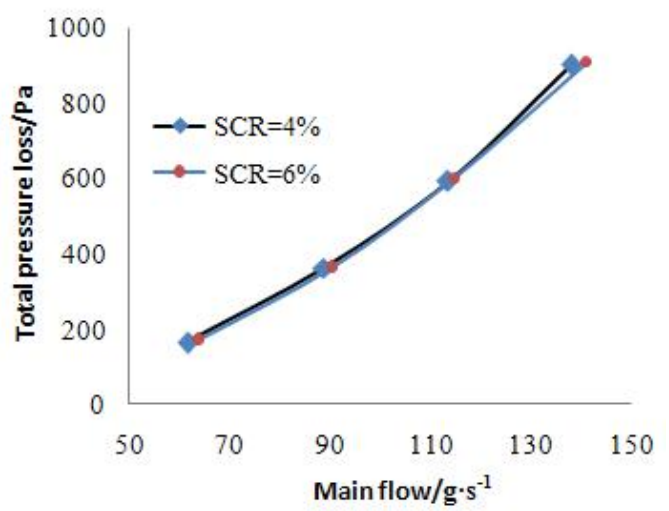

FIGURE IX. RESISTANCE CHARACTERISTIC CURVE AT DIFFERENT SCR AND MAIN FLOW 


\section{CONCLUSIONS}

The good agreement of numerical simulation and experiment in resistance characteristics demonstrates feasibility and accuracy of the numerical simulation method.

The vortex tube's resistance loss increases as SCR and main flow increase, but SCR has a smaller effect compared to main flow.

\section{REFERENCES}

[1] Fan Wenzheng, Yu Haibin. Status and Trends of the Inlet Preventer of Helicopter [J]. Aeronautical Science and Technology, 2000, 1: 31- 32.

[2] Li Liguo, Wang Suofang. Inlet Protection of Engine Helicopter [M] Beijing: National Defense Industry Press, 2009: 2- 3, 77, 84- 85, 91- 96.

[3] Wang Zhongyi, Wang Mingxin. Research Findings Concerning the Effect of Axle Shapes on the Performance of Cyclone Separators [J] Journal of Engineering for Thermal Energy and Power, 2007, 22(1): 21 24.

[4] Luan Yigang, Wang Song, Sun Haiou. Performance Study of an Axialflow Gas-Liquid Cyclone Separator Without Throttleer [J]. Journal of Chinese Society of Power Engineering, 2011, 31(2): 142- 147.

[5] Tao Wenquan.Numerical Heat Transfer [M]. Xi`an jiaotong university press, 2001: 79-81.

[6] Hou Lingyun, Yan Chuanjun. Numerical Simulation of 3-D Two-Phase Flow field in Inlet Particle Separator for Helicopter [J].Journal of Aerospace Power, 2000, 15(2): 215- 218.

[7] A.V Nguyen,C.A.J. Fletcher. Particle Interaction with the Wall Surface in Two-phase Gas-solid Particle Flow [J]. Multiphase Flow, 1997, 25: 139- 154.

[8] M. Sommerfeld. Modeling of Particle-wall Collisions in Confined Gasparticle Flow [J]. Multiphase flow, 1992, 18(6): 905-926. 